\title{
TIME-DEPENDENT PERFORMANCE-BASED DESIGN OF CAISSON BREAKWATER CONSIDERING CLIMATE CHANGE IMPACTS
}

\author{
Seung-Woo Kim ${ }^{1}$ and Kyung-Duck Suh ${ }^{2}$
}

\begin{abstract}
A time-dependent performance-based analysis was conducted to analyze the influences of sea-level rise and waveheight increase due to climate change on caisson sliding of the breakwaters designed in different water depths. We used the Goda's spectral method to overcome the time-consuming problem in the calculation of the wave height at the breakwater site. In general, severe caisson sliding occurred when considering the climate change impacts. However, the influence of sea-level rise on the stability of caisson sliding is insignificant compared with that of wave-height increase. Especially, since the characteristics of caisson sliding are different depending on water depths, we have to establish countermeasure against these features for the design and maintenance of a caisson breakwater.
\end{abstract}

Keywords: caisson breakwater; caisson sliding; performance-based design; climate change impacts

\section{INTRODUCTION}

Vertical caisson breakwaters have been widely used since the monolithic caisson structures are effective in severe coastal environment. Among various failure modes of a vertical breakwater, the caisson sliding is dominant (Goda and Takagi 2000; Takahashi et al. 2000). Thus, in this study, only this failure mode is considered in the calculation of sliding distance. While various design methods have been developed for the structure, the performance-based design method has been recently adopted in the technical standard in Japan (OCDI 2009). This method is useful not only for the design process but also for the maintenance and operation because the displacement (i.e. sliding distance) and exceedance probability are calculated for the lifetime.

The vertical breakwater is influenced by climate change impacts such as sea-level rise and waveheight increase. Since the lifetime of most breakwaters is generally longer than several decades, the breakwater design should consider future coastal environments. Suh et al. (2012) conducted the performance-based design for the East Breakwater No. 4 cross-section at the Port of Hitachinaka in Japan. Because the cross-section was located in deepwater of $24.2 \mathrm{~m}$ (low water level), the sea-level rise rarely influenced the sliding of the caisson. Therefore, in this study, the breakwaters are fictitiously designed in various water depths both inside and outside surf zone and we analyze the influence of climate change impacts including sea-level rise. The water depth of wave breaking is located between 10. $7 \mathrm{~m}$ and $13.4 \mathrm{~m}$ (mean sea level). The five cross-sections in water depths of 8, 12, 16, 20, and $25 \mathrm{~m}$ were designed by using a deterministic design method. The safety factor was used as 1.2 and both tides and storm surges were included to determine geometric variables.

\section{CLIMATE CHANGE IMPACTS}

In order to consider how the climate change impacts are related to the performance-based design of a breakwater, sea-level rise and wave-height increase are used. The prediction is made on the Pacific Ocean side of Japan $\left(130-145^{\circ} \mathrm{E}, 25-40^{\circ}\right)$ from $2000-2100$ years. For future sea-level rise, the result of the A2 scenario of Mori et al. (2011) was used. Mori et al. (2011) estimated the sea-level rise using five different general circulation models with SRES (Special Report on Emission Scenarios) scenarios A1B and A2 of CIMP3 (Phase 3 of the Coupled Model Intercomparison Project). The mean value of sea- level rise calculated by A2 scenario in 2100 is $0.58 \mathrm{~m}$ and this value is slightly larger than the upper limit of the IPCC AR4 (Fourth Assessment Report) of $0.51 \mathrm{~m}$. The mean value rapidly increases with time, and the more the mean value increases, the more the standard deviation increases. In other words, the uncertainty of sea-level rise increases with time as shown in Fig. 1.

Secondly, the extreme deepwater wave height distribution for future wave climate should be determined for the performance-based design. Suh et al. (2012) evaluated the Weibull distributions for the extreme wave height near the Port of Hitachinaka at the end of 20th and 21st centuries with the design variables given by Takata et al. (2003) as follows:

\footnotetext{
${ }^{1}$ Department of Civil and Environmental Engineering, Seoul National University, 1 Gwanak-ro, Gwanak-gu, Seoul 151-744, Republic of Korea. esfpknu7@snu.ac.kr

${ }^{2}$ Department of Civil and Environmental Engineering, Seoul National University, 1 Gwanak-ro, Gwanak-gu, Seoul 151-744, Republic of Korea. kdsuh@snu.ac.kr
} 


$$
\begin{aligned}
& F^{*}(H)=\left[1-\exp \left\{-\left(\frac{H-4.65}{1.27}\right)^{1.0}\right\}\right]^{0.35} ; \quad H_{50}=8.30 \mathrm{~m} \\
& F^{*}(H)=\left[1-\exp \left\{-\left(\frac{H-4.63}{1.72}\right)^{1.0}\right\}\right]^{0.46} ; \quad H_{50}=10.02 \mathrm{~m}
\end{aligned}
$$

where $H_{50}$ is the significant wave height corresponding to the return period of 50 years.

However, it is difficult to predict how the waves will change during 100 years. Suh et al. (2012) assumed that the scale parameter $A(t)$ and the mean rate $\lambda(t)$ increase linearly or parabolically as follows:

$$
\begin{aligned}
& A(t)=1.27+0.0045 t, \quad \lambda(t)=0.35+0.0011 t \\
& A(t)=1.27+4.5 \times 10^{-5} t^{2}, \quad \lambda(t)=0.35+1.1 \times 10^{-5} t^{2}
\end{aligned}
$$

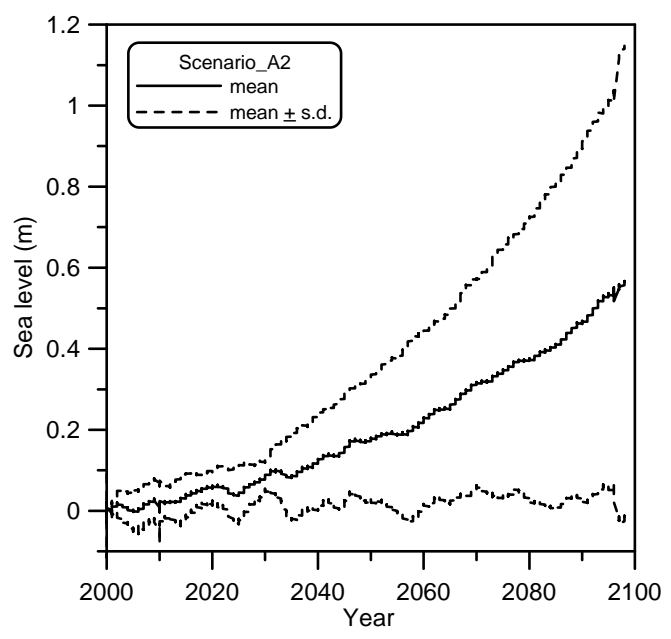

Figure 1. Temporal variation of projected sea-level rise on Pacific Ocean side of Japan by Scenario A2.

\section{WAVES AT THE BREAKWATER SITE}

When the deepwater wave height is determined, the wave height at the breakwater site should be calculated by using the wave transformation model including the wave breaking effect. In the performance-based design, computing time is very important because several thousands of simulations should be performed. To overcome this problem, a simple spectral method is used in this study because the depth-contour is almost straight and parallel to the coastline and the breakwater.

\section{Goda's Spectral Method (Goda 1975; Goda and Suzuki 1975; Kweon and Goda 1996)}

In the present study, a simplified method was developed as follows: (1) Goda's (1975) formula for wave height estimation within the surf zone, (2) Goda and Suzuki (1975) for the calculation of refraction coefficient by using the spectral method for irregular waves, (3) Kweon and Goda (1996) for the evaluation of non-linear shoaling coefficient by using the closure solution.

Goda (1975) proposed an approximate formula for nearshore wave height estimation including the surf zone as follows.

$$
H_{s}=\left\{\begin{array}{lc}
K_{s}^{n l} H_{0}^{\prime} & : h / L_{0} \geq 0.2 \\
\min \left\{\left(\beta_{0} H_{0}^{\prime}+\beta_{1} h\right), \beta_{\max } H_{0}^{\prime}, K_{s}^{n l} H_{0}^{\prime}\right\} & : h / L_{0}<0.2
\end{array}\right.
$$

where $H_{s}$ is the significant wave height at the breakwater site, $H_{0}^{\prime}$ is the equivalent deepwater 
wave height corresponding to the significant wave height, $K_{s}^{n l}$ is the nonlinear shoaling coefficient, $h$ is the water depth, $L_{0}\left(=1.56 T_{s}^{2}\right)$ is the deepwater wave length, and $\beta_{0}, \beta_{1}, \beta_{\max }$ are the coefficients for approximate estimation of wave heights within the surf zone (Goda 1975).

In order to calculate the equivalent deepwater wave height $H_{0}^{\prime}\left(=K_{r}^{\text {eff }} H_{0}\right)$ in Eq. (5), the refraction coefficient is needed. The refraction coefficient for irregular waves can be calculated by

$$
K_{r}^{\mathrm{eff}}=\left[\frac{1}{m_{s 0}} \int_{0}^{\infty} \int_{\theta_{\min }}^{\theta_{\max }} S_{0}\left(f, \theta_{0}\right) K_{s}^{2}(f, h) K_{r}^{2}(f, h, \theta) d \theta_{0} d f\right]^{1 / 2}
$$

where $m_{s 0}=\int_{0}^{\infty} \int_{\theta_{\min }}^{\theta_{\max }} S_{0}\left(f, \theta_{0}\right) K_{s}^{2}(f, h) d \theta_{0} d f, S_{0}\left(f, \theta_{0}\right)$ is the deepwater directional wave spectrum, $K_{s}(f)$ is the shoaling coefficient for regular wave based on linear wave theory, $K_{r}\left(f, \theta_{0}\right)$ is the refraction coefficient for regular wave with frequency $f$ and deepwater wave direction $\theta_{0}$ and $h$ is the water depth. In actual calculation, the refraction coefficient of irregular wave is calculated by

$$
K_{r}^{\mathrm{eff}}=\left[\sum_{i=1}^{M} \sum_{j=1}^{N}(\Delta E)_{i j}\left(K_{r}\right)_{i j}^{2}\right]^{1 / 2}
$$

where the term $(\Delta E)_{i j}$ is expressed as

$$
(\Delta E)_{i j}=\frac{1}{m_{0}} \int_{f_{i}}^{f_{i}+\Delta f_{i}} \int_{\theta_{j}}^{\theta_{j}+\Delta \theta_{j}} S_{0}\left(f, \theta_{0}\right) d \theta_{0} d f
$$

in which $m_{0}=\int_{0}^{\infty} \int_{\theta_{\min }}^{\theta_{\max }} S_{0}\left(f, \theta_{0}\right) d \theta_{0} d f$. In this study, the deepwater frequency wave spectrum and directional spreading function were taken as the modified Bretschneider-Mitsuyasu spectrum (i.e. Pierson-Moskowitz spectrum) and Mitsuyasu-type, respectively. Mitsuyasu-type directional spreading function is given as follows.

$$
G(f, \theta)=G_{0} \cos ^{2 s}\left(\frac{\theta-\theta_{p}}{2}\right), G_{0}=\left[\int_{\theta_{\min }}^{\theta_{\max }} \cos ^{2 s}\left(\frac{\theta-\theta_{p}}{2}\right) d \theta\right]^{-1}
$$

in which $s$ is a parameter related to the frequency with the principal parameter $s_{\max }(=25)$ (Goda 2010). For the Goda's approximate method, the shoaling coefficient is required. Thus, we use the nonlinear shoaling coefficient proposed by Kweon and Goda (1996) with Iwagaki et al.'s (1981) data as follows:

$$
K_{s}^{n l}=K_{s}+0.0015\left(\frac{h}{L_{0}}\right)^{-2.87}\left(\frac{H_{0}^{\prime}}{L_{0}}\right)^{1.27}
$$

Kweon and Goda (1996) employed this functional form and adjusted the coefficients to approximate the Shuto's theory (Shuto 1974). Because the water depth contours are straight and parallel to the coastline near the Port of Hitachinaka, Snell's law is used for wave direction at the breakwater site. Hereafter, this method is called Goda's spectral method.

\section{Uncertainty of Wave Transformation Model}

Most wave transformation models have uncertainty in the calculation of waves at the breakwater site. The estimation error of Goda's spectral method is evaluated by the comparison with laboratory 
experiments. The mean value and standard deviation of the ratio between experimental data and calculated data are expressed as

$$
\begin{gathered}
E\left(\frac{H_{s}^{E}}{H_{s}^{C}}\right)=\frac{\mu_{H_{s}}}{H_{s}^{C}}=1+\alpha_{H_{s}} \\
\sqrt{\operatorname{Var}\left(\frac{H_{s}^{E}}{H_{s}^{C}}\right)}=\frac{\sigma_{H_{s}}}{H_{s}^{C}}=\gamma_{H_{s}}
\end{gathered}
$$

where $H_{s}^{E}$ and $H_{s}^{C}$ are the experimental and calculated significant wave height, respectively. $\alpha_{H_{s}}$ and $\gamma_{H_{s}}$ are the bias and the coefficient of variation of wave model's uncertainty.

Because the bottom of coastal region near the Hitachinaka Port is almost plane and mild slope, Mase and Kirby's (1992) experimental data were used. However, this experiment was conducted at slightly steep slope of 1:20 so that it is not the same test condition as that of Hitachinaka Port. Figure 2 shows the relative frequency of the estimation error of Goda's spectral model. The histogram of this model followed the normal distribution where the mean and standard deviation of the ratio are 0.94 and 0.06, respectively. These statistics of estimation error are similar to those of Kweon et al.'s (1997) model (Hong et al. 2004). The biases of the two models are the same, but the standard deviation of Kweon et al.'s model is larger than that of Goda's spectral model. As mentioned above, Goda's spectral method included the Goda's (1975) approximation formula to consider depth-induced wave breaking inside surf zone. The approximation formula also has an uncertainty to predict the wave height in surf zone depending on the bottom slope. When the bottom slope is 0.1 with the wave steepness 0.02 , this formula slightly overestimated the wave height, but when the bottom slope is 0.01 with the same wave steepness, the wave height was considerably underestimated (Goda 1975). The mean of the ratio is evaluated as 1.04 for the bottom slope of 0.01 . As a result, for Goda's spectral method proposed in the present study, the bias and coefficient of variation are used as 0.0 and 0.1 respectively as shown in Table 1.

Figure 3 shows the significant wave height calculated by the spectral method at the location of the breakwater in water depth of $16 \mathrm{~m}$. In this case, the tidal level and deepwater wave direction are 0.0 and $0^{0}$ respectively. Since the significant wave height at the breakwater site is considerably smaller than the maximum design wave height, the expected sliding distance will be not large in this water depth.

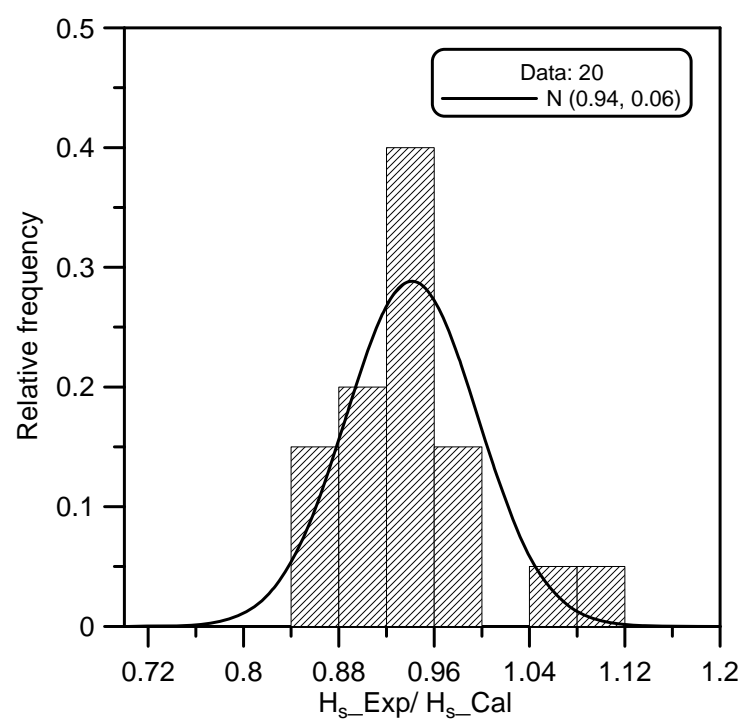

Figure 2. Relative frequency of ratio between the experimental data and calculated one by Goda's spectral method 


\begin{tabular}{|c|c|c|c|}
\hline Wave model & $\operatorname{Bias}\left(=\alpha_{H_{s}}\right)$ & $\mathrm{CV}\left(=\gamma_{H_{s}}\right)$ & Remarks \\
\hline Goda (1975) & -0.13 & 0.09 & $\begin{array}{l}\text { Unidirectional random waves normally incident to plane beach } \\
\text { (Takayama and Ikeda1993) }\end{array}$ \\
\hline $\begin{array}{l}\text { Kweon et al. } \\
\quad(1997)\end{array}$ & $\begin{array}{c}-0.06 \\
-0.06 \\
\text { (truly, }-0.04 \text { ) } \\
0.0\end{array}$ & $\begin{array}{l}0.1 \\
0.1\end{array}$ & $\begin{array}{l}\text { Unidirectional random waves normally incident to plane beach } \\
\text { (Hong et al. 2004) } \\
\text { Directional random waves normally incident to plane beach or } \\
\text { unidirectional waves with some principle wave direction or } \\
\text { effect of variation of principle wave direction } \\
\text { (Hong et al. 2004) } \\
\text { Directional random waves } \\
\text { (Hong et al. 2004) }\end{array}$ \\
\hline $\begin{array}{l}\text { Goda's } \\
\text { approximation } \\
\text { formula (1975) }\end{array}$ & +0.04 & 0.09 & $\begin{array}{l}\text { For bottom slope 1:100, the formula underestimated wave } \\
\text { height compared with Goda (1975) model. }\end{array}$ \\
\hline $\begin{array}{l}\text { Goda's spectral } \\
\text { method }\end{array}$ & -0.06 & 0.06 & $\begin{array}{l}\text { Mase and Kirby (1992), slope } 1: 20 \\
\text { Unidirectional random wave normally incident to plane beach } \\
\text { (Numerical tests in Fig. 2) }\end{array}$ \\
\hline $\begin{array}{l}\text { Goda's spectral } \\
\text { method } \\
\text { (Present) }\end{array}$ & 0.0 & 0.1 & $\begin{array}{l}\text { Directional random waves, } \\
\text { the slope of Hitachinaka Port 1:100 }\end{array}$ \\
\hline
\end{tabular}

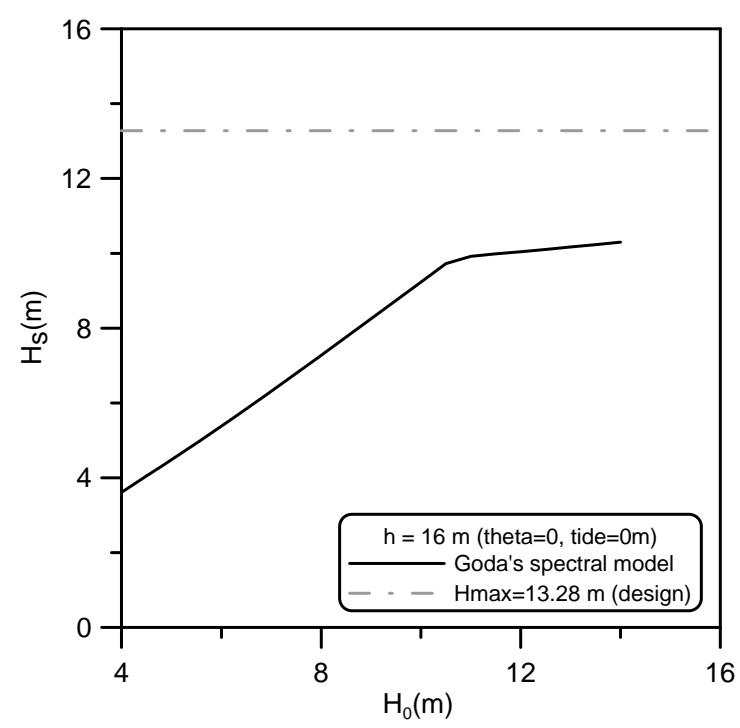

Figure 3. Significant wave height calculated by Goda's spectral method at the breakwater site in $h=16 \mathrm{~m}$

\section{BREAKWATERS DESIGNED BY DETERMINISTIC METHOD}

In this study, the breakwaters are fictitiously designed in various water depths including both inside and outside surf zones in order to analyze the influence of climate change impacts. The water depth of surf zone is calculated by using the relationship between breaking depth $d_{b}$ and breaker height $H_{b}$ proposed by U.S. Army (1984). The deepest breaking water depth is located between 10.7 $\mathrm{m}$ and $13.4 \mathrm{~m}$ below the mean sea level. Therefore, the breakwaters can be designed with five water depth conditions i.e., $8 \mathrm{~m}$ (inside surf zone), $12 \mathrm{~m}$ (wave-breaking zone), $16 \mathrm{~m}$ (outside surf zone), 20 $\mathrm{m}$ (outside surf zone), $25 \mathrm{~m}$ (far outside of surf zone).

The five cross-sections of breakwater were designed by using the deterministic design method of Goda and Takagi (2000) as shown in Table 2 and Fig. 4. The safety factor was used as 1.2 and 
geometric variables included the astronomical and meteorological tides (storm surge, $10 \%$ of deepwater wave height). $H_{\max }, H_{s}, T_{s}$ are respectively the maximum and significant wave height and wave period. $h, h$ ', and $d$ are the depths from sea bottom, caisson bottom, and foot protection block to H.W.L. (high water level) respectively, and $h_{c}$ and $B$ are the crest height and caisson width.

The significant wave height and period and geometric values are evaluated with the design tidal level (H.W.L. with $0.1 H_{0}$ ). The elevation from L.W.L. (datum level) to the design tidal level is $2.33 \mathrm{~m}$. The design deepwater significant wave height and wave period were $8.3 \mathrm{~m}$ and $14.0 \mathrm{~s}$ respectively, corresponding to the return period of 50 years without climate change impacts. Crest height is equal to $0.6 H_{s}$ above the design water level. Thickness of mound is taken as $20 \%$ of the water depth, but at least the thickness should be more than $3.0 \mathrm{~m}$ (Goda and Takagi 2000). Height of foot-protection block and berm width are determined as $1.5 \mathrm{~m}$ and $8.0 \mathrm{~m}$, respectively. The unit weight of upright section and sea water are $20.58 \mathrm{kN} / \mathrm{m}^{3}$ and $10.09 \mathrm{kN} / \mathrm{m}^{3}$. Bottom slope is assumed as $1: 100$ as the same of existing breakwater. Figure 5 shows the design wave height and widths of caisson in different water depths with Table 2. The upper limitation of breaking height proposed by Goda (1974) is also included. We easily expected that the expected sliding distance will be small in water depths smaller than $16 \mathrm{~m}$ because the maximum wave height is limited by wave breaking.

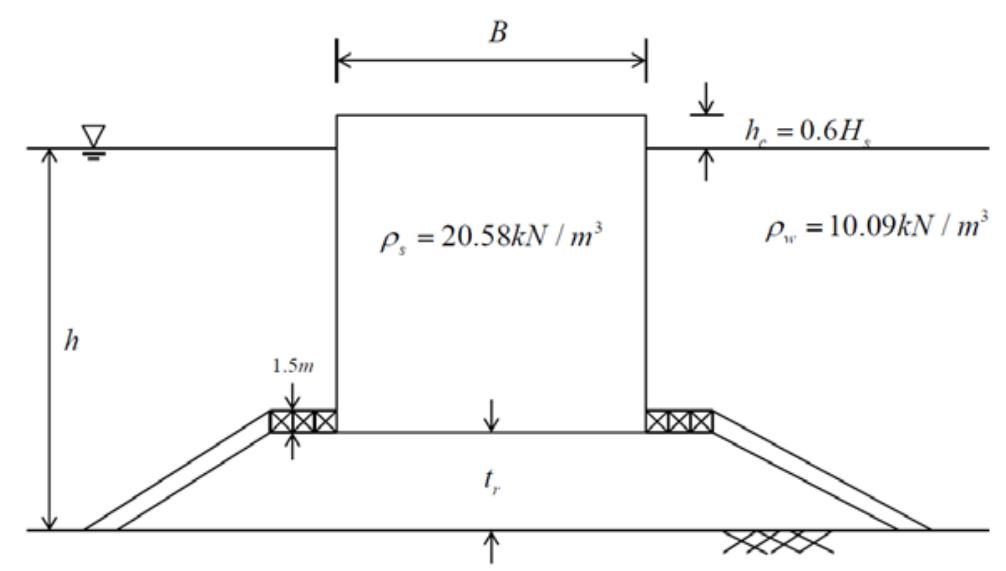

Figure 4. Typical cross-section of vertical breakwater

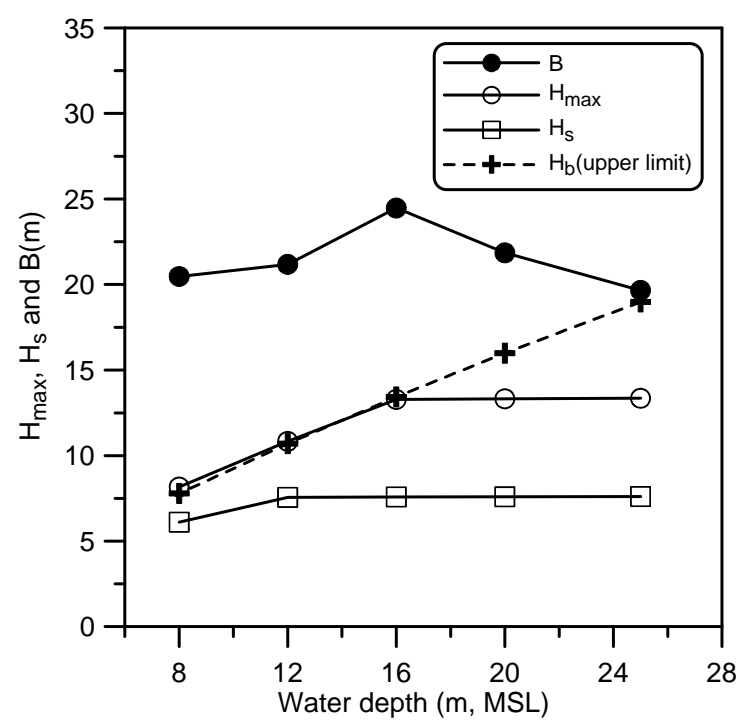

Figure 5. Design wave heights and widths of caisson in different water depths 


\begin{tabular}{|c|c|c|c|c|c|c|c|c|c|}
\hline \multicolumn{10}{|c|}{ Table 2. Design conditions with design tidal level (unit: m, s) } \\
\hline $\begin{array}{c}h \\
(\mathrm{MSL})\end{array}$ & $H_{\max }$ & $H_{s}$ & $T_{s}$ & $B$ & $h$ & $h^{\prime}$ & $d$ & $h_{c}$ & Remarks \\
\hline 8 & 8.16 & 6.11 & 14.0 & 20.47 & 9.58 & 6.58 & 5.08 & 3.67 & $\begin{array}{c}\text { Inside surf zone } \\
\text { Wave-breaking } \\
\text { zone }\end{array}$ \\
12 & 10.83 & 7.56 & 14.0 & 21.18 & 13.58 & 10.58 & 9.08 & 4.54 & $\begin{array}{c}\text { Outside surf zone } \\
16\end{array}$ \\
20 & 13.28 & 7.58 & 14.0 & 24.47 & 17.58 & 14.06 & 12.56 & 4.55 & $\begin{array}{c}\text { Outside surf zone } \\
\text { Existing structure }\end{array}$ \\
\hline
\end{tabular}

\begin{tabular}{|c|c|c|c|c|}
\hline Description & $X_{i}$ & $\alpha_{X_{i}}$ & $\gamma_{X_{i}}$ & References \\
\hline Offshore wave height & various & 0.0 & 0.1 & Shimosako and Takahashi (2000) \\
\hline Significant wave period & various & 0.0 & 0.12 & Suh et al. (2010) \\
\hline Wave transformation & various & 0.0 & 0.1 & Shimosako and Takahashi (2000) \\
\hline Horizontal wave force & various & -0.09 & 0.19 & $\begin{array}{l}\text { Takayama and Ikeda (1993), } \\
\text { Kim and Takayama (2003) }\end{array}$ \\
\hline Vertical wave force & various & -0.23 & 0.20 & Oumeraci et al. (2001) \\
\hline Friction coefficient & 0.6 & 0.06 & 0.16 & $\begin{array}{l}\text { Takayama and Ikeda (1993), } \\
\text { Kim and Takayama (2003) }\end{array}$ \\
\hline
\end{tabular}

\begin{tabular}{|c|c|c|c|}
\hline \multicolumn{4}{|c|}{ Table 4. Test cases with various design conditions } \\
\hline Case & $\begin{array}{c}\text { Sea-level rise } \\
\text { (SLR) }\end{array}$ & Wave-height increase (WHI) & Remarks \\
\hline 1 & $\mathrm{X}$ & $\mathrm{X}$ & Nothing \\
2 & O (A2) & $\mathrm{X}$ & SLR only \\
$3-1$ & $\mathrm{X}$ & O (linear) & WHI only \\
$3-2$ & $\mathrm{X}$ & O (parabolic) & WHI only \\
\hline
\end{tabular}

\section{PERFORMANCE-BASED ANALYSIS}

The vertical breakwaters designed by the deterministic method are analyzed by using the performance-based design method. With this method, the expected sliding distance and exceedance probability can be calculated for each breakwater. Sliding distance of caisson breakwater is calculated by using Shimosako and Takahashi's (2000) method considering time-dependent load variables (i.e. sea -level rise, deepwater wave-height increase) and the uncertainties of design variables in Table 3 were used. Total number of simulations is 50,000 and the expected sliding distance is calculated as the ensemble-average of the sliding distance in each simulation. Especially, Latin hypercube sampling method in the Monte-Carlo simulation was used to select the deepwater wave height in the calculation flow. Table 4 shows the test cases to examine the influence of climate change impacts. The primary aim in this study is to investigate the influence of sea-level rise (A2 scenario) in different water depths. Case 1 is the case in which no climate change impacts were considered. For Case 2 and 3, the influence of sea-level rise and wave-height increase are assessed separately.

Figure 6 shows the expected sliding distance at various water depths without consideration of climate change impacts. The expected sliding distance is very small when the water depth is less than $16 \mathrm{~m}$ as described in the previous section in relation to Fig. 5. In water depths deeper than $16 \mathrm{~m}$, the expected sliding distance rapidly increases with water depth. This is because the maximum wave height is not limited by wave breaking in water depth deeper than $16 \mathrm{~m}$. 


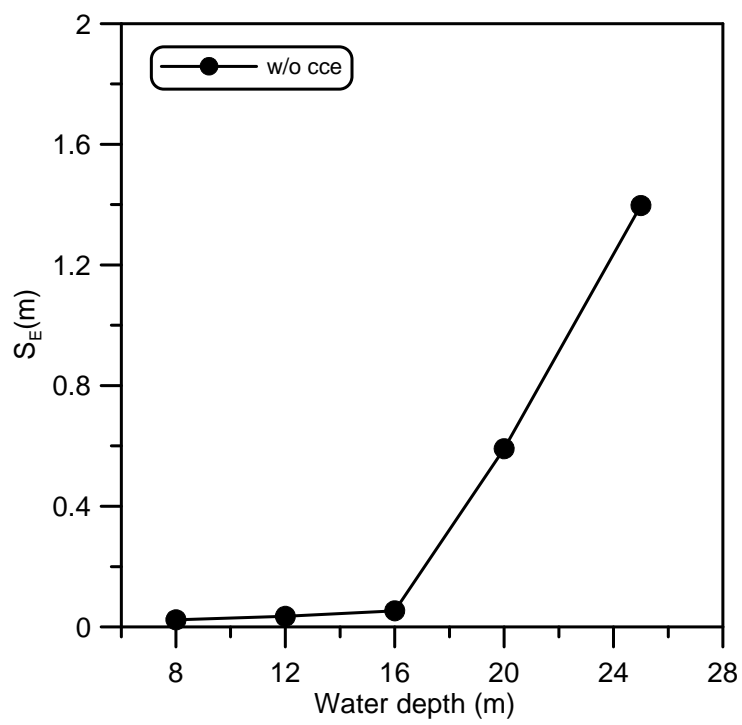

Figure 6. Expected sliding distance versus water depth without consideration of climate change impacts

\begin{tabular}{|c|c|c|c|c|c|}
\hline \multicolumn{6}{|c|}{ Table 5. Expected sliding distance with various water depths $\mathbf{(}_{\mathbf{L}}=\mathbf{5 0}$ years) (unit, $\mathbf{m}$ ) } \\
\hline$h(\mathrm{MSL})$ & w/o & SLR & $\begin{array}{c}\text { WHI } \\
\text { (parabolic) }\end{array}$ & $\begin{array}{c}\text { WHI } \\
\text { (linear) }\end{array}$ & Safe or unsafe \\
\hline 8 & 0.023 & 0.026 & 0.028 & 0.032 & Safe \\
12 & 0.035 & 0.048 & 0.047 & 0.065 & Safe \\
16 & 0.053 & 0.066 & 0.087 & 0.123 & Safe \\
20 & 0.591 & 0.664 & 0.963 & 1.451 & Unsafe \\
25 & 1.397 & 1.432 & 2.167 & 3.214 & Unsafe \\
\hline
\end{tabular}

\section{RESULTS AND DISCUSSION}

Figure 7 and Table 5 show the expected sliding distance calculated with or without consideration of climate change impacts for the breakwaters located in various water depths. The breakwaters located in water depths less than $16 \mathrm{~m}$ are assessed to be safe during the lifetime of 50 years regardless of climate change impacts because the maximum wave heights are limited by wave breaking. When the water depth is greater than $16 \mathrm{~m}$, the expected sliding distance exceeds the allowable sliding distance of $0.3 \mathrm{~m}$ in all the conditions. Comparison between Case 1 and Case 2 shows that the influence of sealevel rise is negligible inside surf zone $(h=8 \mathrm{~m})$ and far outside surf zone $(h=20,25 \mathrm{~m})$, while it is important near the breaker zone $(h=12,16 \mathrm{~m})$. Especially, in the area of $h=12 \mathrm{~m}$, the influence of sea -level rise is almost the same as that of parabolic increase of wave height.

The influence of wave-height increase (Case 3-1 and 3-2) becomes more significant as the water depth increases. It is expected that the influence of wave height is negligible inside surf zone because large waves cannot reach the breakwater due to depth-limited wave breaking. Inside surf zone ( $h=8$, $12 \mathrm{~m}$ ), however, the influence of wave-height increase is greater than that of sea-level rise, especially for the case of linear increase, probably because the waves of moderate height reach the breakwater without breaking.

In summary, outside surf zone, the influence of wave-height increase becomes more significant, while that of sea-level rise becomes negligible, as water depth increases. Inside surf zone, the influences of both wave-height increase and sea-level rise diminish as water depth decreases, but the influence of wave-height increase is greater than that of sea-level rise. Without showing the results, we just mention that the exceedance probability shows similar trends as the expected sliding distance. 


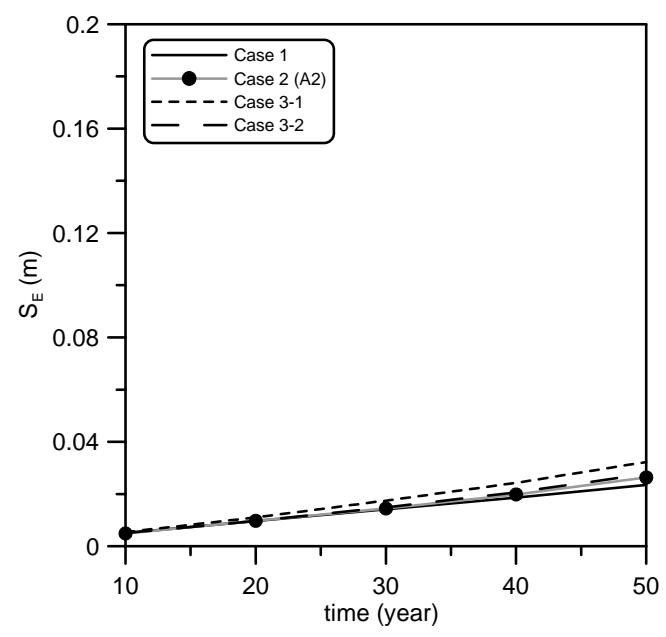

(a)

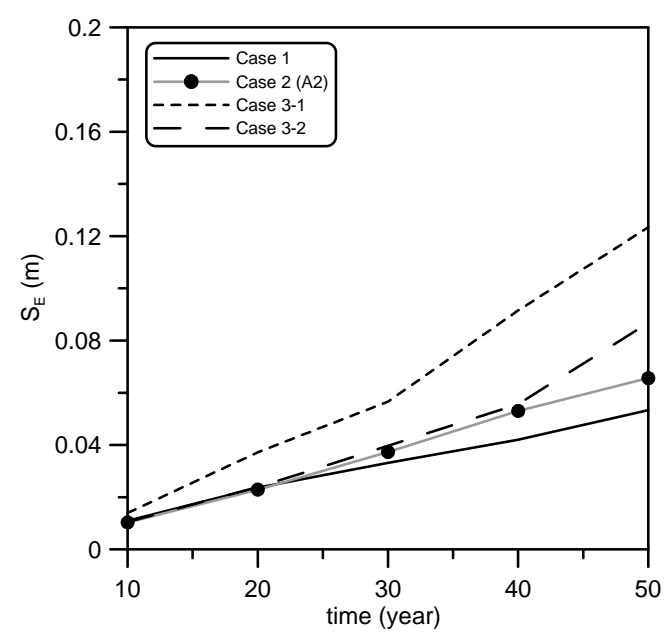

(c)

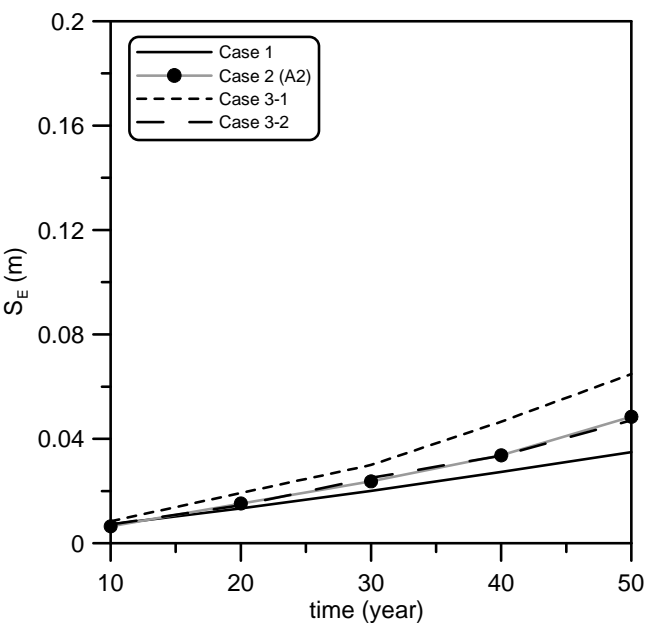

(b)

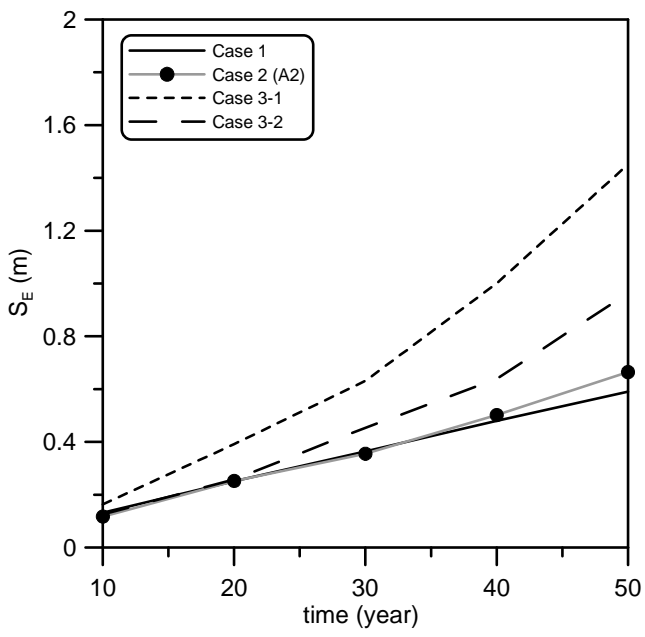

(d)

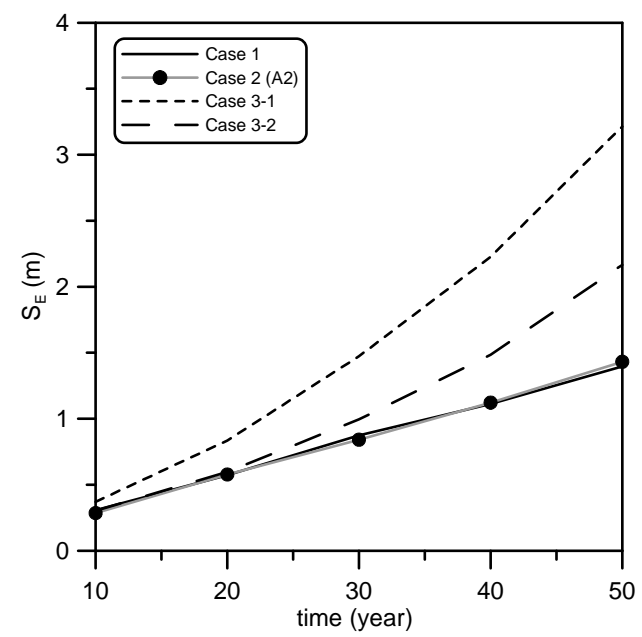

(e)

Figure 7. Expected sliding distance versus time at various water depths (MSL);

(a) $h=8 \mathrm{~m}$, (b) $h=12 \mathrm{~m}$, (c) $h=16 \mathrm{~m}$, (d) $h=20 \mathrm{~m}$, (e) $h=25 \mathrm{~m}$ 


\section{CONCLUSION}

We analyzed the influence of sea-level rise and wave-height increase due to climate change on the stability of caisson sliding of the breakwaters fictitiously designed in both inside and outside surf zones. In order to consider time-variant loads, a performance-based design method was improved. In the calculation process of this method including Monte-Carlo simulation, the Goda's spectral method as a wave transformation method was used to overcome a time-consuming problem. The sea-level rise rarely influenced the caisson sliding both inside surf zone and far outside surf zone. However, since the influence of wave-height increase is larger in deepwater, it is necessary that the design and the maintenance of breakwater is carefully conducted.

\section{AKNOWLEDGMENT}

This research was supported by the Project for Development of Reliability-Based Design Methods for Port and Harbor Structures sponsored by Korea Ministry of Land, Transport and Maritime Affairs. This work was conducted at the Engineering Research Institute of Seoul National University.

\section{REFERENCES}

Kim, T. M. and Takayama, T. 2003. Computational improvement for expected sliding distance of a caisson-type breakwater by introduction of a doubly-truncated normal distribution, Coastal Engineering Journal, 45, 387-419.

Kweon, H.M. and Goda, Y. 1996. A parametric model for random wave deformation by breaking on arbitrary beach profiles, Proceedings of 25th International Conference on Coastal Engineering, ASCE, 261-274.

Kweon, H.M., Sato, K. and Goda, Y. 1997. A 3-D random breaking model for directional spectral waves, Proceedings 3rd International Symposium on Ocean Wave Measurement and Analysis, ASCE, 416-430.

Goda, Y. 1975. Irregular wave deformation in the surf zone. Coastal Engineering in Japan, 18, 13-26.

Goda, Y. 2010. Random seas and design of maritime of structures, World Scientific, Singapore.

Goda, Y. and Suzuki, Y. 1975. Computation of refraction and diffraction of sea waves with Mitsuyasu's directional spectrum. Technical note of Port and Harbour Research Institute 230, pp. 45 (in Japanese)

Goda, Y. and Takagi, H. 2000. A reliability design method of caisson breakwaters with optimal wave heights. Coastal Engineering Journal, 42, 57-387.

Hong, S. Y., Suh, K.-D. and Kweon, H.M. 2004. Calculation of expected sliding distance of breakwater caisson considering variability in wave direction, Coastal Engineering Journal, 46, 119140.

Iwagaki, Y., Shiota, K. and Doi, H. 1981. Shoaling and refraction of finite amplitude waves. In Proceedings of 28th Japanese Conference on Coastal Engineering, 99-103 (in Japanese).

Mase, H. and Kirby, J.T. 1992. Hybrid frequency-domain KdV equation for random wave transformation, Proceedings of 23rd International Conference on Coastal Engineering, ASCE, 474487.

Mori, N., Nakajo, S., Yasuda, T. and Mase, H. 2011. Multi-model ensemble projection of coastal environment under a global warming scenario. Journal of Climate (submitted).

Oumeraci, H., Kortenhaus, A., Allsop, W., De Groot, M., Crouch, R., Vrijling, H. and Voortman, H. 2001. Probabilistic design tools for vertical breakwaters, Balkema, Lisse, Netherlands.

Overseas Coastal Area Development Institute of Japan (OCDI). 2009. Technical standards and commentaries for port and harbor facilities in Japan, Ports and Harbour Bureau, Ministry of Land, Infrastructure, Transport and Tourism (MLIT).

Shimosako, K. and Takahashi, S. 2000. Application of deformation-based reliability design for coastal structures. Proceedings of International Conference of Coastal Structure, 363-371.

Shuto, N. 1974. Nonlinear long waves in a channel of variable section, Coastal Engineering in Japan, 17, $1-12$.

Suh, K.-D., Kim, S.-W., Mori, N. and Mase, H. 2012. Effect of climate change on performance-based design of caisson breakwaters, Journal of Waterway, Port, Coastal, and Ocean Engineering, 138(3), 215-225.

Suh, K.-D., Kwon, H.-D., and Lee, D.-Y. 2010. Some statistical characteristics of large deepwater waves around the Korean Peninsula, Coastal Engineering, 57, 375-384. 
Takahashi, S., Shimosako, K., Kimura, K. and Suzuki, K. 2000. Typical failure of composite breakwaters in Japan, Proceedings of 27th International Conference on Coastal Engineering, ASCE, 1899-1910.

Takata, E., Morohoshi, K., Hiraishi, T., Nagai, T. and Takemura, S., 2003. Distributions of the wave, storm surge and tsunami design conditions on Japanese nationwide coastal structures, Technical Note No. 88, National Institute for Land and Infrastructure Management, Ministry of Land, Infrastructure and Transport, Japan (in Japanese).

Takayama, T. and Ikeda, N. 1993. Estimation of sliding failure probability of present breakwater for probabilistic design, Report 031-05-01, Port and Harbour Research Institute, Ministry of Transport, Yokosuka, Japan, 3-32.

U.S. Army Coastal Eng. Res. Center (1984). Shore Protection Manual 4rd ed., U.S. Government Publishing Office, Washington, D.C., USA. 